\title{
Networked Individual in Networked City: Reviewing Social Network in Transportation Literature
}

\author{
Fariya Sharmeen, Pauline van den Berg, Harry Timmermans \\ Urban Planning Group, Eindhoven University of Technology, Eindhoven, Netherlands \\ Email: f.sharmeen@tue.nl, H.J.P.Timmermans@tue.nl
}

Received 3 February 2014; revised 5 March 2014; accepted 2 April 2014

Copyright (C) 2014 by authors and Scientific Research Publishing Inc. This work is licensed under the Creative Commons Attribution International License (CC BY). http://creativecommons.org/licenses/by/4.0/

c) (i) Open Access

Networks and networking are predominant in individuals' social and professional life. Social media has made networking even simpler in virtual world. To connect and maintain the same in real world, one must depend on transport network. Perhaps it is the effect of the ease and expediency of virtual media that social and recreational trips are increasing every day, reasoning the growing interest of transportation researchers on the indepth analyses of social networks.

In recent years, a stream of transportation literature can be identified emphasizing the importance of studying social networks to improve models of travel demand. Leisure and social activities are responsible for a growing portion of travel. As people's social networks are the main motivator for social activity-travel, research into the characteristics of people's social networks can contribute to an understanding of social travel demand [1]. The international travel behaviour community has picked up this plea [2]-[5]. Recent research into the effect of social networks on transportation has evolved along two lines. The first line of research focuses on the influence that people's social networks have on travel decisions by the exchange of information and opinions. The second line of research focuses on the more direct effects of social networks [6]. Within these lines of research, a distinction can be made between agent based simulations and empirical studies.

The persuasive power of social networks or the activity and travel party cannot be ignored. It can be prerogative in deciding the location, travel mode, duration, distance and other aspects of the trip. Empirical studies comprising the link between personal social networks and travel behavior is still a promising field. In recent times, researchers have addressed several aspects of the influence of social network and activity and travel planning, such as duration, frequency, start time, distance, mode choice, etc (see [5], for detailed review). The reported results are intuitive and demand due attention by the researchers as well as the policy makers and practitioners to incorporate the social context in activity and travel demand forecasting.

To see the big picture, we need to broaden our view from egocentric social network to a population wide projection. Agent based simulation environment is a potential platform to serve the purpose and has been utilized accordingly. Further to simulate the potentiality of a tie formation, the negotiation of a social meeting (mode choice, place, time etc) multi-agent simulation has been employed in transportation research [3] [7] [8].

In order to improve our understanding of the role of social networks in social activity-travel behavior, a series 
of challenges remain on the future agenda. A first challenge is to negate the idea that personal social networks are stagnant. So far, social networks in transportation research have been studied as if they were. On the contrary, it is indeed very much dynamic. People's social network size and composition change over time, sometimes triggered by lifecycle events, such as changing household composition, job or home location. The contemporary shift in travel behavior analysis towards dynamics necessitates the inclusion of social network dynamics. The concept has been coined recently [5].

Regarding data collection on social networks and social activity-travel patterns still some challenges remain as well. To get a good impression of the heterogeneity of leisure activities, it is desirable to collect longitudinal diary data. Traditional travel diary surveys collect one or two days of travel data from participants. While crosssectional travel diary surveys are useful in determining the overall average travel behaviour of the regional population, they do not capture repetitive patterns in social activities, for instance weekly routines of people. New GPS technologies provide a promising way of collecting longitudinal travel data without asking too much effort from respondents.

In addition, the study of the effect of ICT's on social activity-travel remains a topic for future research. Although this topic has been studied recently [4] [9], the possibilities of ICT's are increasing rapidly. These changes will affect social travel, for instance in arranging a social trip (e.g. making reservations, buying tickets, checking routes, weather and travel conditions), making additional research necessary.

A further challenge is to link the a-spatial aspect of social network to the spatial one. There is a spatial facet attached to an individual's social network as far as travel and transportation is concerned. The distance and accessibility of the peers should matter in planning and maintaining social networks [10]. This topic has been largely overlooked by contemporary research. The social environment should not be studied in isolation from the geographical environment.

Finally, the ageing of the population is a topic that deserves future research with regard to social networks and travel behavior. On average, older people have more leisure time compared to younger (working) people. They may therefore spend more time on social activities. On the other hand, the elderly on average have a smaller social network and may be less mobile. Social network analysis can give relevant insights in social activity-travel behavior of senior citizens, as well as matters of accessibility, social capital and social equity.

The analysis of social networks has a far reaching potential in understanding almost all aspects of human behaviour. These potentials have been realized for long. A recent growing field of exploration is activity and travel behaviour. The history of social networks and transportation literatures is nonetheless in an exploration stage. There have been some commendable works already. Further comprehension and integration of the local social context, social externalities and social dynamics to the travel behaviour models remain on the contemporary agenda.

\section{References}

[1] Axhausen, K.W. (2005) Social Networks and Travel: Some Hypotheses. In: Donaghy, K.P., Poppelreuter, S. and Rudinger, G., Eds., Social Aspects of Sustainable Transport: Transatlantic Perspectives, Ashgate, Aldershot, 90-108.

[2] Carrasco, J. and Miller, E. (2006) Exploring the Propensity to Perform Social Activities: A Social Network Approach. Transportation, 33, 463-480. http://dx.doi.org/10.1007/s11116-006-8074-Z

[3] Dugundji, E.R., Páez, A., Arentze, T.A., Walker, J.L. Carrasco, J.A. Marchal, F. and Nakanishi, H. (2011) Transportation and Social Interactions. Transportation Research Part A: Policy and Practice, 45, 239-247. http://dx.doi.org/10.1016/j.tra.2011.01.001

[4] van den Berg, P., Arentze, T. and Timmermans, H. (2013) A Path Analysis of Social Networks, Telecommunication and Social Activity-Travel Patterns. Transportation Research Part C, 26, 256-268. http://dx.doi.org/10.1016/j.trc.2012.10.002

[5] Sharmeen, F., Arentze, T. and Timmermans, H. (2010) Modelling the Dynamics between Social Networks and Activity-Travel Behavior: Literature Review and Research Agenda. Proceedings 12th World Conference on Transport Research, Lisbon, 11-15.

[6] Arentze, T. and Timmermans, H. (2008) Social Networks, Social Interactions, and Activity-Travel Behavior: A Framework for Microsimulation. Environment and Planning B: Planning and Design, 35, 1012-1027. http://dx.doi.org/10.1068/b3319t

[7] Ronald, N., Dignum, V., Jonker, C., Arentze, T. and Timmermans, H. (2012) On the Engineering of Agent-Based Simulations of Social Activities with Social Networks. Information and Software Technology, 54, 625-638. 
http://dx.doi.org/10.1016/j.infsof.2011.12.004

[8] Hackney, J. and Marchal, F. (2011) A Coupled Multi-Agent Microsimulation of Social Interactions and Transportation Behavior. Transportation Research Part A: Policy and Practice, 45, 296-309. http://dx.doi.org/10.1016/j.tra.2011.01.009

[9] Sharmeen, F., Arentze, T. and Timmermans, H. (2013) A Multilevel Path Analysis of Social Network Dynamics and The Mutual Interdependencies Between Face-to-Face and ICT Modes of Social Interaction in The Context of LifeCycle Events. In: Roorda, M.J. and Miller, E.J., Eds., Travel Behaviour Research: Current Foundations, Future Prospects, Lulu Press, Toronto, 411-432.

[10] Sharmeen, F., Arentze, T.A. and Timmermans, H.J.P. (2014) Dynamics of Face-To-Face Social Interaction Frequency: Role of Accessibility, Urbanization, Changes in Geographical Distance and Path dependence. Journal of Transport Geography, 34, 211-220. http://dx.doi.org/10.1016/j.jtrangeo.2013.12.011 